Revista Iberoamericana, Vol. LXXV, Núm. 228, Julio-Septiembre 2009, 795-818

\title{
GENEALOGÍA DE LA "RAZA LATINA": \\ PARA UNA TEORÍA ATLÁNTICA DE LAS \\ ESTRUCTURAS RACIALES HISPANAS
}

\author{
POR \\ Joseba GABILONDO \\ Michigan State University
}

\section{RAZA LATINA Y RETORNO GLOBAL DEL ATLÁNTICO HISPANO}

La "raza latina”, según se formula y elabora en el Atlántico hispano y también en el europeo del xix, es una articulación e ideología que desafía el discurso racial biológico nor europeo que se consolida a mediados de dicho siglo. ${ }^{1} \mathrm{La}$ "raza latina" se articula para posicionar a Latinoamérica y España estratégicamente respecto a los impulsores de dicha ideología racial biológica: el imperialismo inglés y el francés, así como el emergente imperialismo norteamericano. El nuevo discurso racial biológico nor europeo que se desarrolla desde la Ilustración (J. F. Blumenbach e Immanuel Kant), se consolida en la década de 1850 con la publicación de obras como The Inequality of Human Races ${ }^{2}$ del Conde de Gobineau, precisamente en la década en que el concepto de "raza latina" comienza a formularse a ambos lados del Atlántico. Por eso, es importante subrayar que el discurso de la "raza latina" se articula de manera atlántica y triangulada en el siglo xix. Así, en el siglo xx se convierte en la ideología dominante de los países hispánicos a ambos lados del Atlántico, y pasa a celebrarse como "Fiesta/Día de la raza" para conmemorar el "Descubrimiento".

Sin embargo, el término "raza latina" parece haber desaparecido del horizonte intelectual y social del Atlántico hispano contemporáneo, con excepción del

1 Este artículo se presentó como una ponencia: "The Return of the Barbarian Divide: For a Genealogy of Modern Racial Discourse in Spain and Europe (from Castelar and Unamuno to Aznar and Azurmendi, via Vasconcelos)" en la conferencia "What's New?: Transatlantic Luso-Spanish Debates and the Market of Ideas” organizada por el Department of Romance Languages and Literatures, University of Michigan. Querría agradecer a los organizadores y especialmente a Cristina Moreiras Menor.

2 He decidido citar las obras en las lenguas en que las he consultado para que de esta manera haya coherencia entre las referencias y la bibliografía. Muchas de estas obras se pueden encontrar en traducciones al castellano; sin embargo, todas las citas de obras en otros idiomas son traducción propia. 
discurso chicano y aquí ya como "raza” sin la calificación de "latina” (Pérez Torres). Solamente el concepto complementario de "mestizaje” sigue usándose en el discurso latinoamericano, aunque a veces el mismo denote no una realidad racial, sino una mezcla cultural. En este contexto, el "mestizaje” pasa a reformularse en términos que parecen describir de manera más acertada la realidad heterogénea que produce la problemática de la modernización/modernidad en Latinoamérica: sincretismo, transculturación (Ortiz, A. Rama) e hibridación (García Canclini). Asimismo, el término español que se elabora a partir del de "raza latina" en la década de 1890, "casticismo", ha caído igualmente en desuso. Sin embargo, la ideología del excepcionalismo español que se sigue proponiendo como identidad nacional en todo el siglo xx oscila entre el casticismo y el orientalismo, entre la nostalgia imperialista y la celebración subalterna de su otredad "gitano-árabe": la España diferente que era reserva espiritual de Occidente y simultáneamente paraíso exótico turístico para Europa del Norte. Más recientemente, en la década de los 90, esta misma España casticista vuelve, con la energía del retorno de lo reprimido, en una nueva formulación neoliberal que funde la celebración del neoimperialismo español en Latinoamérica con una reacción anti ilustrada respecto a Europa y que, por tanto, rescata la idea de la excepcionalidad española.

Como lo demuestra la continua reformulación de "raza latina” en "mestizaje/ casticismo" y, más tarde, en "transculturación/hibridación/excepcionalismo", el siglo XIX da lugar a un proceso de reformulación ideológica del problema racial que llega hasta nuestros días y cuya función es precisamente la de hacer desaparecer o naturalizar el racismo como tal. La mayoría de los críticos e historiadores concuerdan en el hecho de que la ideología racial del mestizaje/casticismo se define por su flexibilidad e inconsistencia discursiva (Graham 2-3, Miller 3-5), pero nadie ha vindicado todavía el hecho de que dicha inconsistencia sea precisamente la que la hace ideológicamente exitosa. Dicha flexibilidad ideológica da lugar a extensiones no-raciales del fenómeno, de tal manera que hoy día se puede contemplar simultáneamente el uso étnico del término "raza" en la cultura chicana, el uso desracializado en el discurso intelectual latinoamericano (transculturación, hibridación) o el uso neoliberal en la España global (excepcionalismo).

Este artículo se propone explicar por qué la flexibilidad "desracializante" de la ideología del mestizaje/casticismo se origina precisamente en la articulación de la "raza latina" en el siglo xIx. Por una parte, dicha formulación representa la transformación poscolonial latinoamericana del antiguo sistema racial español -basado en la pureza de sangre y la genealogía- a uno nuevo de "raza latina”, el cual será posteriormente asimilado de nuevo por la España posimperialista en la ideología del “casticismo”. Por otra parte, esta transformación poscolonial responde a un ajuste del antiguo orden racial colonial genealógico a las nuevas teorías raciales 
biológicas del imperialismo europeo del siglo xix. Es decir, la transformación poscolonial de la "raza latina” da lugar a la nueva raza "moderna”, que se adecua al nuevo racismo imperialista europeo pero que, al mismo tiempo, establece una diferencia geopolítica no-moderna e irreducible respecto a dicho sistema racial. Esta doble transformación poscolonial es la que provee la flexibilidad ideológica a la "raza latina”. En consecuencia, dicha flexibilidad ideológica pasa a definir la ideología racial que se propagará en el siglo xx en Latinoamérica y España a través de una creciente constelación de términos, como raza latina, raza cósmica, la raza, mestizaje, transculturación, hibridación, casticismo, hispanismo, excepcionalismo e identidad latina (en Estados Unidos). Esta variedad terminológica demuestra la continuidad histórica de la "raza latina”, que su flexibilidad ideológica permite y legitima.

En realidad, el concepto de "raza latina” parte del discurso racial imperialista español, que no es biológico en su sentido moderno (color de piel y fisonomía) sino genealógico (pureza de sangre y descendencia), y se posiciona como nueva raza "moderna” dentro del imaginario racista que elaboran el imperialismo alemán y francés. A diferencia del imperialismo inglés o norteamericano, el francés y alemán toman como referencia la "universalidad" del imperialismo romano, de ahí el énfasis en lo "latino”. Son estos dos países europeos los que, a mediados del siglo XIX, planifican nuevas expansiones imperialistas destinadas a competir con el imperialismo británico. Dada la naturaleza flexible del término "raza latina”, éste será usado por intelectuales y políticos alemanes, latinoamericanos, franceses y españoles en un complejo y contradictorio tráfico de apropiaciones, negaciones y acusaciones, que continuará en la primera mitad del siglo xx en Latinoamérica y España, y más tarde, a través de José Vasconcelos, en el mundo chicano. Por lo tanto, más que de un mestizaje racial, podríamos hablar de un "mestizaje histórico" de teorías e ideologías raciales (española-renacentista/europea-decimonónica) que hacen de la "raza latina” una teoría e ideología simultáneamente moderna y nomoderna. Es esta naturaleza doble/mestiza de la ideología de la "raza latina” la que permite crear el efecto de “democracia racial” que se impone en Latinoamérica y España en el siglo xx como ideología hegemónica de las nuevas elites nacionalistas. Más aún, es la hibridación ideológica e histórica de lo no-moderno y lo moderno de la "raza latina” la que sustenta su triangulación atlántica (Europa/Latinoamérica/ Estados Unidos) y su legitimación geopolítica.

Este trabajo es una arqueología en el sentido de una investigación de la organización discursiva del poder (siguiendo las propuestas de Foucault). Hoy día, y como consecuencia de la emergencia de nuevos discursos racistas en el mundo hispánico globalizado, es necesario volver a analizar la "raza latina” en su complejidad triangular y atlántica, para comprender y explicar algunos de los 
aspectos más específicos de aquellos, no en su inexplicable novedad, sino en su continuidad con su antecesor, la "raza latina". Por eso, es necesario emprender una genealogía rigurosa del término "raza latina" que describa su triangulación geopolítica atlántica e historice su hibridación, evitando así los problemas que Paul Gilroy produce al ignorar a África en su propuesta del Atlántico Negro.

\section{LA ILUSTRACIÓN Y EL TRAUMA DEL MESTIZAJE Y LA DEGENERACIÓN}

Frente al racismo genealógico del colonialismo español renacentista, la Ilustración noreuropea desarrolla un modelo racial diferente que es necesario investigar en detalle, para poder analizar cómo la raza latina surge en la intersección de ambas formaciones raciales. Frente a la primera clasificación racial propuesta por Carl von Linné en su historia natural, la cual sólo contemplaba cuatro razas diferentes, Johann Friedrich Blumenbach, fundador alemán de la antropología física, propone una nueva clasificación de cinco razas en la tercera edición de 1795 de On the Natural Variety of Mankind (1775). Dicha clasificación agrupa a las Américas bajo la rúbrica homogeneizante de "roja". A su vez, la relación de Blumenbach con Immanuel Kant y la publicación de la antropología de éste último, donde cita a Blumenbach (Anthropology 211), permite que dicha clasificación se popularice hasta el siglo xx.

Lo que caracteriza al discurso de ambos autores es su ansiedad racista respecto a la degeneración y la mezcla, procesos que, de acuerdo con estos autores, se alimentan mutuamente. Basándose en Buffon, Blumenbach defiende que la raza blanca o caucásica (término inventado por él mismo) es la representante más pura de la raza original humana; el resto de las razas surgen como degeneración de la misma, siendo la etíope (negra) y la mongol (amarilla) las más degeneradas (26566). A su vez, Kant, en su Anthropology from the Pragmatic Point of View (1798), declara que la mezcla lleva al empeoramiento y a la degeneración de las razas: "Por lo tanto, podemos concluir con certitud que la mezcla de razas (causada por conquistas a gran escala), la cual extingue gradualmente las características de aquellas, no parece ser beneficiosa para la raza humana” (236). En su discusión del carácter español, Kant ya apunta que es precisamente la mezcla de la "sangre española” con la "árabe” la que define a España como no-europea (Anthropology 231-32).

A su vez, cuando Kant se refiere anteriormente a las Américas en Observations of the Feeling of the Beautiful and the Sublime (1764) y "On the Different Races of Man” (1775), él mismo sitúa a la raza americana fuera de la civilización occidental y del proyecto imperialista de ésta y, como consecuencia, la describe como una raza que no puede sumarse a la historia debido a la falta de energía y resolución de la que padece. En sus Observations, Kant todavía distingue entre indígenas 
norteamericanos y sudamericanos, y sólo acusa a los últimos de apatía e incapacidad para la civilización:

Entre todos los salvajes, no hay nación que demuestre un carácter mental más sublime que la de los de Norteamérica [...] El resto de los nativos de esta parte del mundo [Sudamérica] da pocas muestras de un carácter mental con disposición para sentimientos refinados; una extraordinaria apatía constituye la característica de este tipo de raza. (111-12)

Pero en su artículo sobre las diferentes razas humanas, escrito once años más tarde, dicha acusación se generaliza a toda la raza americana (“On the Different” 46). Finalmente, en algunos de sus apuntes póstumos que luego pasan a compilarse como Physical Geography, Kant, citando a un autor español, vuelve a la idea de Sudamérica como incapaz de ser civilizada por su carencia de inteligencia e iniciativa (64). Aunque algunas de estas afirmaciones provienen claramente de la literatura española colonial precedente, su recontextualización en la filosofía de la Ilustración les da un nuevo significado que las sitúa de manera excluyente fuera de la civilización y la historia teleológica e ilustrada de Occidente. Por lo cual, y a diferencia de otros discursos raciales de la época, Kant sitúa la raza americana en la parte inferior de la jerarquía racial que se define por su nivel de mezcla y degeneración. En Physical Geography, Kant escribe: "[L]a humanidad se halla en su grado más alto de perfección en la raza de los blancos. Los indios amarillos tienen un talento reducido. Los negros están situados mucho más abajo y en la base se encuentra una parte de los pueblos americanos” (63).

De todos modos, es importante resaltar que Kant, cuando habla de "América", por lo general no se refiere tanto a Latinoamérica como a Norteamérica y a su "raza roja/cobriza", la cual es una raza que no se ha mezclado con la blanca. Latinoamérica se convierte en una zona que, debido a la mezcla racial que surge con el imperialismo español, no puede clasificarse como raza roja. Como apunta en uno de sus comentarios sobre un gobernador mexicano que se negó al mestizaje, éste actuaba de acuerdo con la ideología racial biológica que desaconseja la mezcla y, por lo tanto, recibe el beneplácito de Kant (citado en Poliakov 353).

Por eso, Latinoamérica se convierte en un horizonte traumático para la nueva ideología del racismo biológico. Latinoamérica no es una sola raza distinta (la roja) sino el área geográfica mestiza que desafía la epistemología del nuevo discurso racial iluminista. Esto se ve sobre todo cuando Kant comenta el mestizaje latinoamericano entre esclavos, criollos e indígenas en su descripción de África y su raza; dicho mestizaje termina creando un trauma geopolítico que desplaza Latinoamérica a África (Physical Geography 60-61). El mismo trauma se repite al intentar localizar a España dentro de Europa. 
Este trauma y esta resistencia racial que provoca Latinoamérica (y España) se perpetuará en el siglo xix. El Conde de Gobineau ya caracteriza a las Américas como el escenario más representativo en su tesis general de que "[L]a civilización es incomunicable, no sólo a los salvajes, sino incluso a naciones más ilustradas" (171). Así, Gobineau, refiriéndose a los indígenas de la América del Sur y del Norte, concluye que, como resultado de la mezcla, son los españoles los que "han bajado" al nivel de los indígenas (46). Para Gobineau, la civilización no se puede transmitir a una raza inferior $y$, por el contrario, una raza inferior tiene el potencial de degradar a una superior si se da la mezcla racial. Es decir Latinoamérica, una vez más, se presenta como un trauma racial para las civilizaciones y razas europeas.

Es esta resistencia racial latinoamericana (y española) a la clasificación, ordenación y tabulación de la Ilustración y, posteriormente, del positivismo, la que permite a Latinoamérica y a partes de Europa desarrollar un nuevo discurso racial alternativo. Aunque Francisco Bilbao sea reconocido como el inventor de los términos “América latina” y "raza latina” en 1856, ya en 1807-1808 Fichte publica su Addresses to the German Nation, donde apunta a una nueva teoría racial y lingüística que incluye la categoría de "latino" y/o "neo latino". En dicha obra, Fichte sitúa a Alemania en el centro geográfico del asentamiento de la raza blanca europea, denominada germánica, la cual es definida por oposición a su versión degenerada: la bárbara "neo latina". Esta ordenación racial se debe al objetivo de Fichte de convertir a Alemania en el líder del futuro europeo posnapoleónico (8687). En la obra de Fichte, la denominación "neo latino" se refiere precisamente al imperialismo romano que concluye teleológicamente con la expansión francesa y la invasión napoleónica y, por extensión, también incluye a todos los países de idiomas romances: la raza latina.

Fichte empieza por presentar a la raza alemana como la raza original europea que va a conducir a Europa a un futuro poslatino - es decir, a un futuro posterior a la teleología romano-francesa. Según Fichte, Alemania puede combinar la religión cristiana con la cultura greco romana en el emplazamiento geopolítico racial correcto, la blanca Europa:

la raza alemana [Der Deutsche] es una rama de la teutónica [Stamm der Germanier, 595]. De la última digamos sólo que su misión fue combinar el orden social establecido en la Europa antigua con la religión verdadera preservada en Asia [cristianismo] y, de esta manera, desarrollar en sí y para sí una era diferente después de que el mundo antiguo hubiera perecido. (45)

Para justificar su teleología, Fichte mantiene que las poblaciones que hoy día hablan lenguas romances también son de origen germano y por tanto la diferencia fundamental entre pueblos latinos y alemanes no es racial sino lingüística. Dado 
que la mezcla sigue siendo abyecta y traumática para el discurso racial romántico, Fichte prefiere concluir que los "latinos" son originalmente alemanes a pesar del mestizaje (47). Para Fichte, la pérdida del idioma original (el alemán) y la adopción del latín por parte de las tribus germánicas que se trasladaron al sur de Europa supone la verdadera mezcla y degradación (56). Esta degradación se debe, según Fichte, al hecho de que los países que hoy día hablan idiomas romances viven bajo una alienación filosófico-lingüística producida por la evolución del latín en lenguas romances o neo-latinas, que a su vez interrumpe la conexión natural del hablante romance con la lengua materna latina. Es esta alienación que sólo sufren los pueblos "neo latinos" (que hablan lenguas romances) la que separa a los alemanes de los neo latinos y sitúa a estos últimos en la base de la nueva jerarquía filosófico-lingüística en la que los germano hablantes ocupan la posición superior (58-59).

Aunque la división es lingüística y no racial, el hecho de que se sobreponga a una clasificación originalmente racial (la raza germánica) crea efectos racializantes que llevan a Fichte a usar términos como "linaje latino". Como consecuencia, las traducciones inglesas y francesas de la obra crean el término "raza (neo)latina" para capturar el original de "Römischen Stämme”: “Aquí me refiero especialmente a Italia, la sede principal de la cultura neo latina de aquella época, ya que el resto de razas neo latinas [Römischen Stämme, 630] iban a la zaga en todo” (79). De esta manera, aunque ya se acepta la influencia de Fichte en los movimientos pan alemanes y pan eslavos, queda por afirmar que también influye en la creación del pan latinismo que más adelante celebrarán el imperialismo francés, las élites criollas latinoamericanas y la aristocracia reaccionaria española.

Es precisamente esta nueva formulación, que oscila entre lo lingüístico y lo racial, y que significa ambos sin reducirlas a ninguno de los dos, la que da a la ideología de raza latina la flexibilidad ideológica que la definirá en el transcurso del siglo xix. Es ésta una categoría que es simultáneamente racial y no-racial, europea y no-europea, moderna y no-moderna.

\section{RAZA LATINA Y MESTIZAJE EN EL DISCURSO LATINOAMERICANO POSCOLONIAL ${ }^{3}$}

El concepto de raza latina se formula el mismo año en que surge el término “América latina” en la conferencia que da el intelectual chileno Francisco Bilbao en París en 1856: "Iniciativa de la América. Idea de un congreso federal de las repúblicas”. Bilbao se referirá a “raza latina” y “raza Latinoamericana” (10).

Dado que en los estudios latinoamericanos la atención se ha centrado en el problema de Latinoamérica, la discusión sobre Bilbao se enfoca en dicho término,

3 Para el propósito de esta genealogía y por limitaciones editoriales, dejamos fuera gran parte del corpus crítico que se ocupa de la temática y de los autores primarios que aquí se discuten. 
olvidando que Bilbao no se refiere tanto a una Latinoamérica geopolítica sino a una raza latinoamericana de la cual luego se deriva Latinoamérica como proyecto político de federación republicana. En dicha conferencia, la primera vez que Bilbao hace referencia a Latinoamérica, la presenta como raza: “¿Habrátan poca conciencia de nosotros mismos, tan poca fe de los destinos de la raza Latinoamericana, que esperemos a la voluntad ajena y a un genio diferente para que organice y disponga de nuestra suerte?” (10). Incluso en la segunda referencia a Latinoamérica, ésta se debe entender como raza, ya que se opone a la latina e indígena: "Pero la América vive, la América latina, sajona e indígena protesta, y se encarga de representar la causa del hombre" (11). Por fin, en la tercera y última cita a "Latinoamérica”, Bilbao vuelve a invocar el concepto de raza: "Tenemos que desarrollar la independencia, que conservar las fronteras naturales y morales de nuestra patria, tenemos que perpetuar nuestra raza americana y latina” (12). Aunque en estas tres referencias todavía se podría argumentar que el concepto de "raza latina” está más cerca del de civilización/cultura o incluso del de genealogía, Bilbao explica que Latinoamérica puede igualarse a Norteamérica y a sus éxitos históricos precisamente en el espíritu democrático de su política racial -en el sentido moderno-biológico de la palabra raza:

Hemos hecho desaparecer la esclavitud de todas las Repúblicas del Sur, nosotros los pobres, y vosotros los felices y ricos [EEUU] no lo habéis hecho; hemos incorporado e incorporamos a las razas primitivas, formando en el Perú la casi totalidad de la nación, porque las creemos nuestra sangre y nuestra carne, y vosotros las extermináis jesuíticamente [...]. No vemos en la tierra, ni en los goces de la tierra el fin definitivo del hombre; y el negro, el indio, el desheredado, el infeliz, el débil, encuentra en nosotros el respeto que se debe al título y a la dignidad del ser humano. (16-17)

Finalmente, y cuando Bilbao adelanta una serie de leyes que debiera aprobar la futura confederación latinoamericana que él propone, se vuelve a colar entre las mismas el discurso racista biológico y civilizador que proponen en el continente latinoamericano Sarmiento y Alberdi: " 8 o. Un sistema de educación universal y de civilización para los bárbaros” (23).

En otras palabras, Bilbao, desde presupuestos republicanos-liberales radicales, introduce toda la flexibilidad que el concepto de raza latina adquirirá en la segunda mitad del siglo. Es también importante apuntar que Bilbao percibe tanto a Europa como a la teleología romano-francesa como parte del pasado de una humanidad que, de forma muy hegeliana, se va a resolver en América, en "el más vasto palenque de dos razas [la latina y la sajona]” (21). Es decir, en Bilbao, la referencia latina no es en ningún modo francófila o euro céntrica; lo latino le sirve de ideología racial para situarse frente al avance de los Estados Unidos. 
En realidad, la conceptualización de una raza latina es desarrollada en la década de 1850 por escritores latinoamericanos y es posteriormente retomada tanto por autores franceses, preocupados por una nueva ideología que legitime la expansión imperialista francesa en Latinoamérica, como por autores españoles, interesados en mantener la ascendencia posimperial española en Latinoamérica. La formulación de Bilbao, que también impulsará el colombiano José María Torres Caicedo, ${ }^{4}$ debe por tanto situarse históricamente entre la anexión estadounidense del norte de México en 1848, por una parte, y la invasión francesa de México (1861) y la anexión de la República Dominicana a la Corona española (1861), por la otra.

Después de la invasión francesa de México, en La América en peligro, Bilbao abandona la formulación de "América/raza latina” y la denuncia como maquinación francesa. Es precisamente en ese momento cuando Bilbao establece la genealogía racial alemana de dicho concepto:

El origen de la teoría es germánico -pero lo que los filósofos alemanes habían demostrado a favor de laAlemania, los eclécticos doctrinarios franceses, plagiando el fondo, aplicaron la forma a Francia. La teoría es esta:

La filosofía alemana demostró, que todo el trabajo de los siglos, o más bien, que las manifestaciones de la idea absoluta, tenían en los pueblos germánicos la encarnación definitiva. El Oriente fué un momento del infinito, o el Reino del Padre, en toda la magnificencia de la fuerza. El mundo griego romano fué otro momento del infinito, o el Reino del Hijo. El mundo moderno fué el tercer momento de la Idea, que llegaba a la conciencia de sí misma, en el Reino del Espíritu.

Si cada momento tuvo sus razas o naciones que lo representaran, el tercer momento le tocó a Alemania.

¿Qué hace [Victor] Cousin? Acepta la teoría, pero en lugar de la Alemania puso a la Francia. (54-55)

Aunque en los debates posteriores la atención de la mayoría de los críticos pasa al nombre de Latinoamérica, desde la formulación de Bilbao dicho concepto va unido al de raza latina. El gobierno de Napoleón III fundó la Revue des Races Latines (1857-1861), que en España se duplicó con la fundación de la revista Raza Latina $(1874-1884){ }^{5}$

La formulación que desarrollan Bilbao y Torres Caicedo responde a una nueva triangulación atlántica que reescribe no sólo la historia latinoamericana, sino la de los imperialismos europeo y norteamericano. Por una parte, la referencia a lo latino se convierte en una forma de distanciarse del imperialismo español, ya que ahora la América hispana poscolonial deja de ser española para pasar a ser latina. Por otra

4 Como apunta Vicente Romero, las ideologías de Bilbao y Torres Caicedo están contrapuestas ya que aquel, siguiendo a Lamennais, apuesta por el republicanismo y éste por la monarquía (21).

5 “La Revista española” de ambos mundos comienza en 1853 y se publica hasta 1855. 
parte, la referencia a la latinidad recentra la historia de Latinoamérica fuera de la esfera española y dentro de la de la modernidad europea que Francia representa de una manera ideal, ya que ésta no posee una historia imperialista en Latinoamérica hasta entonces y, en la concepción de Bilbao, forma parte del pasado de la historia de la humanidad. A su vez, la nueva alineación latinoamericana con la modernidad europea pretérita la distancia del creciente imperialismo norteamericano (aunque en un momento Bilbao hable de "La Alianza con los Estados Unidos"; La América 56). En este contexto, la formulación racial latinista también permite la vuelta a un bolivarismo que, después de la invasión francesa de México, pasa a definirse de manera antiimperialista tanto respecto a Europa como a los Estados Unidos.

Esta triangulación atlántica racial no se puede resolver sólo en términos geopolíticos e históricos, es decir, con la referencia a una Latinoamérica que es estrictamente problema y proyecto político: la referencia a la raza, en su nuevo sentido moderno y flexible, es fundacional para Bilbao. Bilbao radicaliza todavía más su discurso racial y pasa a condenar cualquier iniciativa "civilizadora” como "imperialismo":

La Francia jamás ha sido libre [...] La Francia jamas [sic] ha sufrido por la libertad del mundo [...].

Pero ha llegado la hora de despertar. Es necesario arrancar el error y libertarnos del servilismo espiritual de la Francia [...]. [Ésta] se presenta sin pudor, con todo el cinismo de una librea del imperio, en flagrante delito, robando, asesinando y perjurando en gran escala, en Europa, en África, en Asia y en América [...] Y todo a nombre de la civilización. (La América 50-52)

Torres Caicedo, por su parte, aunque siempre defendió los intereses franceses y ocupó una posición relevante dentro de los círculos políticos y culturales franceses, también se decantó por una nueva forma de bolivarismo en su obra Unión latinoamericana. Pensamiento de Bolívar para formar una liga americana, su origen y desarrollo (1865). Por su parte, Bilbao, que fue perseguido por sus ideas anticlericales y republicanas, no tuvo éxito en su propuesta de eliminar la pobreza en Latinoamérica. En este sentido, la idea de una Latinoamérica de raza latina iba en contra de los intereses de las clases criollas oligárquicas de la mayoría de los países latinoamericanos. De todos modos, Bilbao ocupa una posición central en el discurso antiimperialista latinoamericano del siglo xIX y en ese sentido es un precursor (Rojas Mix 349; Mignolo 71).

En la segunda mitad del siglo xIX, el concepto de raza latina será reapropiado por los intelectuales más radicales de Latinoamérica, pero, precisamente porque el resituamiento racial de Bilbao ha tenido éxito, dichos autores ya no se referirán a una raza pan latina que se oponga a la sajona. Por el contrario, asumirán el problema de 
la raza como central a la constitución de cada república y, por eso, pasarán a hablar de "nuestra/la raza” y del “mestizaje” como procesos centrales de la construcción nacional. Escritores como Manuel González Prada, José Enrique Rodó, Justo Sierra, José Martí y Eugenio María de Hostos articularán un nuevo discurso racial del mestizaje que será heredero de la flexibilidad ideológica de la raza latina. Por un lado, estos autores presentarán lo racial como el problema central de la historia latinoamericana y, a su vez, propondrán el mestizaje como la nueva ideología que convierte a todo individuo racialmente marcado en sujeto del estado, y por tanto en individuo “sujetado” por el estado. En el discurso del mestizaje, el estado es la institución que reconoce al individuo racialmente marcado como sujeto puramente político y, por tanto, no marcado racialmente. Así, el estado termina por legitimar el racismo como problema políticamente inexistente y que, por tanto, emigra al ámbito de la “cultura” y del “arte”. Es decir, el discurso del mestizaje oscilará entre la denuncia de la explotación racial y la legitimación del control estatal del individuo racialmente marcado que pasa a ser sujeto político no marcado racialmente. Pedro Henríquez Ureña resume bien el problema cuando en 1913 concluye:

Creo indiscutible la afirmación de que existe un carácter, un sello regional, un espíritu nacional en México. Para concebirlo, para comprenderlo, hay que comenzar, a mi juicio, por echar a un lado la fantástica noción de raza latina, a que tanto apego tiene el demi-monde intelectual. Sólo ha de hablarse de cultura latina, o, en rigor, novolatina. (24)

De forma preeminente, José Martí articula la nueva transformación de "la raza latina” en la de "nuestra América mestiza” en su artículo "Nuestra América” (1891). Lo que interesa a Martí no es la celebración del mestizaje como nueva realidad y teleología racial de Latinoamérica, sino precisamente la desaparición del problema racial bajo la nueva equiparación del individuo mestizo con la de sujeto de estado ("hombre natural”), por lo cual simultáneamente el problema racial se afirma en su universalidad de ciudadanía y se niega como particularidad histórica ("no hay razas”). Primero, Martí equipara mestizo con ciudadano: "Los hombres naturales han vencido a los letrados artificiales. El mestizo autóctono ha vencido al criollo exótico” (17). A partir de la universalización natural del mestizo como único ciudadano de la república latinoamericana, Martí pasa a negar la historia particular del conflicto racial en Latinoamérica y, consecuentemente, convierte esta negación en teleología e ideología racial: "No hay odio de razas, porque no hay razas” (20-22). ${ }^{6}$

\footnotetext{
6 En "Mi raza”, Martí añade: “Esa de racista está siendo una palabra confusa y hay que ponerla en
} claro. El hombre no tiene ningún derecho especial porque pertenezca a una raza o a otra: dígase 
Por lo tanto, la estructura ideológica flexible de la raza latina persiste en Martí. Lo que diferencia a Martí de pensadores posteriores del siglo xx, como Vasconcelos, es que el discurso racial del mestizaje sirve de denuncia anticolonial y antiimperialista. En su artículo “Mi raza” (1893), Martí es consciente de la relación raza/imperialismo:

Los derechos públicos, concedidos ya de pura astucia por el Gobierno español e iniciados en las costumbres antes de la independencia de la Isla, no podrán ya ser negados, ni por el español que los mantendrá mientras aliente en Cuba, para seguir dividiendo al cubano negro del cubano blanco, ni por la independencia, que no podría negar en la libertad los derechos que el español reconoció en la servidumbre. (300)

De la misma manera, Eugenio María de Hostos, en su artículo "El día de América”, ya vaticinando la celebración oficial que de dicha fecha se hará precisamente bajo el nombre de "Día de la raza”, apunta a la nueva flexibilidad ideológica de "la raza mestiza":

Tres razas madres, la autóctona, la conquistadora y la africana, han regado con su sangre el Continente [...]

Pero lo incomprensible es que no sean en general bien apreciados los dos mayores beneficios que el Nuevo Continente ha hecho al porvenir de la Humanidad.

Esos dos beneficios, complemento el uno del otro, coinciden tan exactamente con el probable destino del Hombre en el planeta y con la secular tendencia de su naturaleza, que harán de América el centro de gravedad del mundo, el fundamento de todas las civilizaciones, el seno común de la Humanidad del porvenir [...]. El camino del Pacífico era el camino del ideal americano; la fusión de las razas en una misma civilización. La Federación era la meta del ideal del Nuevo Mundo; la unión de todas las naciones. (16-19)

Y, en su artículo “El Cholo” (1870), Hostos volverá a retomar la doble y flexible tarea de generalizar la ideología de raza como mestizaje y así negar la historia racial:

El Nuevo Mundo es el horno donde han de fundirse todas las razas, donde se están fundiendo [...]. América deberá su porvenir a la fusión de razas; la civilización

hombre, y ya se dicen todos los derechos. El negro, por negro, no es inferior ni superior a ningún otro hombre; peca por redundante el blanco que dice: "Mi raza"; peca por redundante el negro que dice: "Mi raza”. Todo lo que divide a los hombres, todo lo que especifica, aparta o acorrala es un pecado contra la humanidad” (298). 
deberá sus adelantos futuros a los cruzamientos. El mestizo es la esperanza del progreso. $(152-53)^{7}$

Todavía cuando Hostos escribe este artículo (1870), el estado controlado por las elites criollas no ha pasado a reconocer al mestizo como ideal de ciudadano, por lo cual el discurso de Hostos tiene valor de denuncia y crítica de la discriminación al cholo.

La formulación racial y geopolítica de una Latinoamérica posicionada de manera triangulada respecto a los imperialismos europeo y norteamericano abrió el camino para que dicha formulación racial sirviera de base para la ficción e ideología estatal del mestizaje. Por lo cual, la articulación y los usos de la ideología de la raza latina constituyen desarrollos eminentemente atlánticos que reflejan una triangulación imperialista en lo más íntimo de su organización discursiva: su flexibilidad discursiva e histórica de lo latino a lo mestizo.

RAZA LATINA Y MISSION CIVILISATRICE EN EL DISCURSO IMPERIALISTA FRANCÉS Y NORTEAMERICANO

La discusión sobre el origen de la palabra "Latinoamérica" ha oscurecido el hecho de que la ideología imperialista de la "raza latina” ya está presente en el panorama intelectual y político desde la década de 1830. Michel Chevalier, colaborador del gobierno de Napoleón III, escribe con anterioridad a la conferencia de Bilbao de 1856 dos reseñas de la obra de Prescott sobre la conquista de México ("De la civilisation mexicaine avant Fernand Cortez” y "La conquête du Mexique par Fernand Cortez”, 1845), donde ya prevee y justifica el expansionismo francés en Latinoamérica recurriendo al latinismo (Chevalier, Mexico). Pero ya desde sus Lettres sur l'Amérique du Nord (1836), escritas como resultado de su visita a los Estados Unidos, Chevalier articula el intervencionismo francés en Latinoamérica de forma pan latinista. En la carta treinta y cuatro, Chevalier declara, siguiendo el discurso iluminista que iguala mestizaje y degeneración, la necesidad de la intervención francesa:

Parece por tanto que los angloamericanos están llamados a continuar directamente y sin ayuda exterior la serie de progresos que la civilización a la que pertenecemos ha estado siempre realizando [...] mientras que los hispanoamericanos no parecen ser sino una raza impotente que no dejará posteridad, a no ser que, como resultado

\footnotetext{
José Enrique Rodó representaría la formulación más conservadora de este paradigma. Como afirma en su Ariel: "Pero en ausencia de esa índole perfectamente diferenciada y autonómica, tenemos -los americanos latinos- una herencia de raza" (209).
} 
de uno de esos desbordamientos que se llaman conquistas, un fluído de sangre más rica, venida del norte o del levante, llene sus empobrecidas venas. (43)

Más adelante, y siguiendo el mismo esquema racial del romanticismo alemán, Chevalier diferencia entre raza germánica/anglosajona, latina y eslava. Como afirma el autor en una carta anterior:

En nuestra Europa de tres cabezas, la latina, la alemana y la eslava [...] Francia es depositaria de los destinos de todas las naciones del grupo latino en los dos continentes [...], Francia me parece que está llamada a ejercer un patronato benefactor y fecundo sobre los pueblos de la América del Sur, los cuales no están todavía en estado de valerse por sí mismos. (9-10)

Simultáneamente La Revue des Races Latines, publicada sin interrupción en París desde 1857 a 1861, sirve como órgano propagandístico del pan latinismo francés. Como apunta Vicente Romero, la revista se llamaba originalmente Revue espagnole et portugaise y servía de tribuna pública para la política francesa de la península ibérica (64). Romero cita la nueva editorial de 1857 que propone la apertura americana: "sostendremos y probaremos que la raza latina es superior [a la raza anglosajona], y que las antiguas colonias españolas y portuguesas, independientes hoy día, están llamadas a destinos más brillantes que el de los Estados Unidos” (64). Es por lo tanto en este contexto latinista de la política y la intelectualidad francesa donde se debe situar la intervención de Bilbao.

En plena invasión francesa a México, Chevalier publica, en la Revue des deux mondes, dos artículos (1862) donde defiende la superioridad atlántica de la raza latina sobre la anglosajona (y germánica) así como la centralidad de Francia. Pero en estos artículos tardíos, Chevalier sólo está condensando las tesis que ya había elaborado en las décadas de 1830 y 1840. Otros autores, como el clérigo Emmanuel Doménech y Edgar Quinet, se harán eco de este pan latinismo francés y usarán el término de América latina y raza latina. Incluso Lamartine, en su conocida carta a Torres Caicedo, concluye: "Los americanos del Norte no han llevado al Nuevo Mundo sino la civilización materialista, fria [sic] como el egoismo [sic], ávida como el lucro, prosáica [sic] como el mercantilismo anglo-sajon [sic]. Vds. han llevado las virtudes y los gustos elevados de la raza latina” (Torres Caicedo, Ensayos vii). De todos modos, el fracaso francés en México y su derrota posterior en la guerra franco-prusiana clausuran el intervencionismo pan latinista de Francia en el Atlántico. De aquí en adelante, el debate de la raza latina se centrará en Latinoamérica y España.

A su vez, el imperialismo norteamericano será el único que no hará uso de la formación de la raza latina, ya que cualquier tipo de referencia al mestizaje 
amenaza su propio sistema racial, definido por el opuesto principio de separación y contención de razas. Como apunta Anna Brickhouse, el senador y secretario de Estado Edward Everett, ya en 1821, defendía que la raza latina era una raza “mixta y corrupta” que sólo produce “degeneración” (4). Por lo tanto, y desde la retirada francesa de México, el ideal racial de la latinidad se convertirá en un discurso ideológico exclusivo de España y Latinoamérica, donde dicho discurso se desplegará domésticamente para imponer una ideología criolla o reaccionaria y usar la amenaza imperialista atlántica europeo-norteamericana como elemento exterior de contención.

RAZA LATINA Y ESCLAVITUD EN EL DISCURSO ESPAÑOL POSIMPERIAL

Antes de que el debate sobre la raza latina se expanda a España en 1857, el discurso racial español se divide en dos polos excluyentes que representan la oscilación entre el discurso genealógico colonial y el biológico noreuropeo, y que se aplican respectivamente al continente latinoamericano y africano. Sólo con la irrupción de la ideología de la raza latina cambiará dicho divorcio de discursos raciales que pasarán a unificarse precisamente bajo la nueva ideología latinista.

Como demuestra Susan Martín Márquez en su Disorientations, el discurso arabista tiende a una celebración multiracial de la Edad Media española en la primera mitad del siglo xIx. Sin embargo, y como apunta la misma autora, en la segunda mitad del siglo dicho discurso arabista llega a amplios círculos intelectuales donde se intenta contraatacar con una ideología orientalista conservadora. Incluso el discurso regeneracionista de Joaquín Costa cambiará de una vindicación de las raíces árabes y musulmanas de España a una condenación racista de dichos orígenes. Finalmente, los nacionalismos periféricos del norte (vasco, gallego y catalán) optarán por usar el mismo discurso racista español respecto a África para diferenciarse del resto del estado español, alineándose así con Europa y distanciándose de una España que también perciben como africana.

La intensificación orientalizadora del discurso arabista español es paralela a la que sufre la propia España a manos del discurso romántico noreuropeo, incluido el francés, el cual se centra en el sur de España y más concretamente en la comunidad gitana y/o romaní, en lo que se podría condensar como “el efecto Carmen”. Este discurso representa la ansiedad española respecto a los nuevos proyectos imperialistas europeos en África; de ahí que España tienda a desidentificarse con su pasado “africano" y, a su vez, lo compense desplegando dicho discurso europeo racista hacia África. La Guerra de África de 1859-1860, en su fracaso final, simboliza la culminación del discurso biológico racial: España fracasa en su intento de convertirse en potencia europea expansionista y pasa a ser “colonizada” por el capital y el turismo europeos. 
Al mismo tiempo, hay un segundo discurso racial genealógico colonial que vuelve a desplegarse dentro de España para resolver el problema de la pérdida colonial latinoamericana. Como ha apuntado José Álvarez Junco, el nacionalismo promovido por los liberales españoles toma como punto de partida las guerras napoleónicas de comienzos del siglo xix para construir un discurso nacionalista español de expulsión del invasor a manos del "pueblo" (119-49). Dicho autor también subraya que la guerra contra la invasión napoleónica sólo se empieza a llamar "Guerra de Independencia” en la década de 1830 (127-28), precisamente después de las guerras de independencia latinoamericanas. Un aspecto que todavía no se ha explorado en profundidad es el hecho de que el nacionalismo español liberal adopte el discurso poscolonial latinoamericano de "independencia" para imaginar a España como nación -en el sentido que Benedict Anderson da a "comunidad imaginada” (14)- después de haber sido profrancés (afrancesado) antes de la invasión. Es decir, la España posimperial se imagina como colonia latinoamericana para articular su nueva identidad nacional en una Europa centrada en una modernidad que, irónicamente, es definida por el "invasor” francés. Dicha imaginación nacionalista permitirá que la continuidad poscolonial/imperial entre España y Latinoamérica pase a afirmarse de manera negativa, ya que ahora la única “colonia emancipada” es precisamente la nación española, y así se reprime tácitamente la historia americana de emancipación colonial.

En la primera mitad del siglo xix, y con la excepción de Cuba y Puerto Rico, el discurso respecto a Latinoamérica desaparece del imaginario cultural español. Esta desaparición permite seguir legitimando el esclavismo colonial español en Cuba y Puerto Rico, ya que la emancipación de estas colonias no se percibe como posibilidad histórica similar a la del resto de Latinoamérica. Sólo en la década de 1850, cuando el discurso de la raza latina pasa de Francia y Latinoamérica a España, la ausencia poscolonial latinoamericana se hace presente como discurso y realidad histórica que el reflejo del discurso francés pan latinista fuerza a convertir en presencia positiva. El problema de Latinoamérica como pérdida posimperial, representada en la raza latina, vuelve a convertirse en un problema histórico que, a su vez, desencadena los primeros discursos en contra de la esclavitud en las colonias españolas de Cuba y Puerto Rico, un hecho que el discurso de la raza latina desnaturaliza y convierte en problema. Será precisamente Emilio Castelar quien desarrolle ambos discursos simultáneamente y, por tanto, podrá consolidar el discurso racial biológico respecto a África (y a España como país “africano”) y el discurso racial genealógico respecto a Latinoamérica en una sola nueva ideología flexible: la raza latina.

La ideología de la raza latina permitirá a Castelar denunciar la esclavitud como práctica que no se puede integrar dentro de la nueva ideología española de raza latina 
y que, por tanto, se debe abolir (Discursos 259-62). El discurso de la raza latina será adoptado para reescribir en clave española la ideología francesa de mission civilisatrice: la misión civilizadora que España llevó a cabo ya en el Renacimiento y con respecto a la cual ahora Latinoamérica tiene una deuda histórica pendiente. Esta deuda poscolonial se hace presente en la continuidad racial entre España y Latinoamérica y se evidencia en la raza latina. Como dicha deuda es consecuencia de la acción civilizadora española, aquella requiere que la esclavitud desaparezca de las colonias para que España pueda equipararse al resto de naciones europeas en su nuevo rango de imperio civilizador/civilizado: el esclavismo se convierte en signo de barbarie española. A su vez, la nueva ideología española de la raza latina requiere que la deuda poscolonial latinoamericana se pague con un nuevo alineamiento latinoamericano fuera de la esfera francesa (y norteamericana) y dentro de la española, una influencia que los liberales desean pero sólo pueden representar como pérdida/deuda imperialista simbólica.

Como apunta Arturo Ardao, parte de la obra de Chevalier se había traducido ya para 1853 en la Revista española de ambos mundos (67-68). El mismo año y en la misma revista, el dominicano Francisco Muñoz del Monte publica un artículo titulado “España y las repúblicas hispanoamericanas”, que se volverá a reeditar en 1857 en La América. En el mismo, Muñoz del Monte afirma que la unión entre España y Latinoamérica está definida por la ideología de la raza latina:

no son sólo los intereses comerciales, el provecho del mutuo cambio; no son sólo el imperio simpático de la sangre, la identidad del dogma religioso, la comunidad de las tradiciones históricas y la analogía necesaria de los sentimientos, de las costumbres, de los gustos y de las tendencias. Hay otro interés superior que absorbe a todos los demás intereses para fundirlos en uno solo. Ese interés es el de la conservación de la raza latina. (citado en C. Rama 244-45)

De manera similar, en 1857, Emilio Castelar publica en La América el artículo “El porvenir de nuestra raza”, que recibe réplica de mano del escritor colombiano José María Samper en los artículos “La cuestión de las razas” y "La unión hispanoamericana” (C. Rama 266). En "El porvenir de nuestra raza”, Castelar esboza la reapropiación liberal española del discurso de raza latina como deuda poscolonial respecto al imperio civilizador, España, la nueva Roma renacentista (C. Rama 310).

En un discurso que pronuncia en el congreso de diputados en 1870, Castelar articula de manera más extensa la nueva ideología española de la raza latina. Castelar combina la deuda poscolonial con la abolición de la esclavitud en un solo discurso que, como consecuencia, pasa a legitimar la nueva misión civilizadora española que se equipara con la norteamericana: España puede ser los nuevos Estados 
Unidos (norteamericanos) de Europa. El texto merece ser citado en extensión por su claridad ideológica:

Sí, hay tres pueblos que parecen muertos, los tres pueblos más excepcionalmente grandes: el pueblo griego [...] el pueblo romano [...] el pueblo español, que dilató el mundo de la naturaleza de la creación, que tendió sus manos creadoras sobre el solitario océano, y al descubrir América dobló la tierra, ensanchó el espacio [...]. Sí; aquel pueblo de gran territorio y mucha población que realice reformas sociales radicalmente, como es la abolición de la esclavitud; aquel pueblo que sepa prescindir de una dinastía histórica, de una Iglesia oficial, de un ejército numeroso; aquel pueblo que sepa ejercer la libertad de imprenta sin escándalo, la libertad de reunión sin excesos, el sufragio universal sin cesarismo, será en Europa lo que los Estados Unidos son en América: será el ideal y la esperanza de todos los pueblos [...]. Nosotros no somos sólo una potencia europea; nosotros hemos sido, y seremos siempre, una potencia americana [...]. Nos importa tener en aquellos continentes no un dominio material, ya irremisiblemente perdido, sino un grande influjo moral. ¿Qué debemos hacer para esto, señores diputados? Debemos dar un gran ejemplo a América. La raza latina nos necesita; necesita de España para contrarrestar el ímpetu de la raza sajona: nosotros necesitamos de América para dilatar nuestro espíritu, para tener grande espacio donde desarrollar nuestra actividad, grandes objetos que responden a nuestra idea. (259-62)

Una vez que la abolición de la esclavitud empieza a implementarse en la España colonial (1880-1886), los elementos más reaccionarios de la intelectualidad española se apropiarán del discurso liberal de la raza latina. En 1881, un discurso de Marcelino Menéndez Pelayo hace patente el giro netamente reaccionario que toma dicho discurso:

Brindo [...] por la fe católica, apostólica, romana, que en siete siglos de lucha nos hizo reconquistar el patrio suelo, y que en los albores del Renacimiento abrió a los castellanos las vírgenes selvas de América [...]. Brindo por la nación española, amazona de la raza latina, de la cual fué escudo y valladar firmísimo contra la barbarie germánica y el espíritu de disgregación y de herejía que separó de nosotros las razas septentrionales. (385, énfasis mío)

Así, a finales de siglo, el discurso racial de la latinidad se concentra en el Atlántico hispano pero, precisamente porque España y Latinoamérica se triangulan respecto a los Estados Unidos y Europa, el discurso de la raza latina adquiere toda la flexibilidad que supone su doble origen genealógico y biológico: mientras que en España se convierte en un discurso reaccionario y melancólico de la pérdida colonial (ya total después de 1898), en Latinoamérica pensadores radicales como Martí y Hostos se proponen rescatar el mestizaje de la raza latina para crear una Latinoamérica diversa, 
simultáneamente moderna y no-moderna. Es precisamente la amplitud y flexibilidad ideológica del doble discurso racial latino la que dará lugar, a principios del siglo xx, a la celebración del comienzo de la conquista española de Latinoamérica con el nombre de "Día de la raza".

DÍA DE LA RAZA Y DEMOCRACIA RACIAL

En 1913, Faustino Rodríguez San Pedro, presidente español de la Unión Iberoamericana, decide impulsar una nueva iniciativa para denominar el día en que Colón llega a las Américas como la "Fiesta de la raza" (Bueno Sánchez). Dicha denominación, posteriormente bautizada como "Día de la raza”, se extiende tanto en España como en Latinoamérica hasta 1958, cuando empieza a cambiar de nombres: Día de la hispanidad, Día del descubrimiento de dos mundos, Día de las Américas y Día de la resistencia indígena. En México, el "Día de la raza” lo promueve en 1928 el ministro de cultura José Vasconcelos, autor de La raza cósmica.

Este es el momento en que la ideología de la raza latina alcanza su máxima expansión y en el que el discurso nacionalista modernizador se generaliza en Latinoamérica y España. Es éste también el momento cuando los Estados Unidos consolida su política imperialista de intervención en toda Latinoamérica, y más tarde en España con la apertura de bases militares americanas en la década de 1950. Como consecuencia, el discurso de la raza se nacionaliza y por tanto pierde su contenido progresista de finales de siglo en Latinoamérica, para pasar a convertirse en la ideología hegemónica de la nación.

Por otro lado, en España dicho discurso da lugar al discurso del casticismo y la hispanidad, según lo promueve Miguel de Unamuno. Como ya apuntara a finales del siglo xix en su En torno al casticismo: “[D]e raza española fisiológica nadie habla en serio y, sin embargo, hay casta española, más o menos en formación, y latina y germánica, porque hay castas y casticismos espirituales por encima de todas las braquicefalias y dolicocefalias habidas y por haber” (3: 26-27). Aunque Unamuno parece negar el discurso racial biológico, en el mismo texto, más adelante, pasa a movilizar simultáneamente el racismo biológico y genealógico. En un párrafo rara vez citado, Unamuno compara las circunvalaciones geográficas del imperio español con las del cerebro "superior" del europeo: "puede decirse que el tener el europeo más periférico el cerebro que el negro de África es reflejo de tener Europa más perímetro de costa, seis veces más respecto al área que el África” (3: 92). Más tarde, en 1912, cuando se discute la Fiesta de la raza, Unamuno añade:

[L]a fiesta de la Raza espiritual española no debe, no puede tener un sentido racista material -de materialismo de raza [...]. Hay que alejar de esa fiesta todo 
imperialismo que no sea el de la raza espiritual encarnada en el lenguaje. Lenguaje de blancos, y de indios, y de negros, y de mestizos, y de mulatos”. (6: 911)

Es decir, Unamuno legitima el discurso de la raza latina como mestizaje imperialista. De la misma manera, Vasconcelos, en su Raza cósmica (1927), propone un mestizaje universal donde toda raza pueda confluir en la ideología del estado nacionalista modernizador: "Para no tener que renegar alguna vez de la patria misma es menester que vivamos conforme al alto interés de la raza” (9).

A partir de esta hegemonización de la ideología de la raza latina a principios del siglo xx, los diferentes discursos de mestizaje sólo servirán para legitimar el nuevo racismo ideológico del proyecto de la nación-estado moderna, incluso en su variante comunista. Es esta historia del mestizaje en el siglo xx que Marilyn Miller explora en su Rise and Fall of the Cosmic Race. Como apunta John Beverley en una mirada retrospectiva a las dos formulaciones más exitosas de la ideología del mestizaje, la transculturación (Ortiz; A. Rama) y la hibridación (García Canclini) están genealógicamente unidas (126).

RETORNO DE LA RAZA LATINA

Desde principios de la década de los 90, cuando los efectos de la globalización se empiezan a sentir en Latinoamérica y en España, el proyecto de la nación-estado modernizadora entra en crisis y curiosamente el problema de la raza latina vuelve a surgir con toda la flexibilidad racial e ideológica que la caracteriza desde sus orígenes decimonónicos. Por una parte, los discursos sobre la hibridación (cultural) empiezan a resurgir y, por otra, una nueva ideología racista, que se amolda a los nuevos criterios norteamericanos, impone un nuevo concepto de "blancura" que niega todo mestizaje en el Atlántico Hispano.

Hoy en día, el racismo hispánico global reúne fenómenos tan diferentes como el de los emigrantes colombianos y ecuatorianos en España, las nuevas movilizaciones antinacionalistas de indígenas en varias partes de Latinoamérica, la presencia hispana como minoría étnica que desafía las categorías clásicas del discurso racial en los Estados Unidos, el nuevo discurso histórico y racial del capitalismo español en Latinoamérica, etc. La reemergencia global del discurso racial hispano se caracteriza precisamente por afirmar y negar simultáneamente la diferencia hispana como racial (y no racial); es por esta flexibilidad ideológica que dicho discurso global representa una continuidad con el de la "raza latina".

La legitimación del "nuevo" discurso racial hispano se agudiza con las nuevas generaciones de jóvenes que han crecido en la globalización. En el 2000, Escárraga, en el El país digital publica un artículo interesante sobre la opinión de los jóvenes 
sobre la inmigración. Según el periodista, el Instituto de la Juventud del gobierno español publicó dos encuestas en 1995 y 2000 respectivamente, que ya contenían fraseología racista en los mismos cuestionarios. A la pregunta de si la inmigración era perjudicial "para la raza”, el 55\% de los jóvenes respondió positivamente en 1995. Sin embargo, en la encuesta del año 2000, la misma pregunta recibía un porcentaje positivo menor, $30 \%$, lo cual sólo significa que el racismo español ha pasado a adquirir la flexibilidad ideológica que lo caracteriza históricamente, ahora disfrazada de corrección política. De la misma manera, y en lo que concierne a Latinoamérica, George Reid Andrews subraya el alza del racismo de jóvenes skinheads en Brasil, Colombia, Uruguay y Venezuela, y se une a Alfredo Chacón al concluir que el único cambio que ha habido en los últimos quince años es que el racismo se ha hecho más “aceptable, inconsciente y normal” (Andrews 195).

Este "resurgimiento" global del racismo hispano no se puede denunciar como un fenómeno inusitado y sin precedentes. Tal denuncia sólo ayudaría a legitimar el siglo xx como un período de "democracia racial". Por el contrario, hay que estudiar el racismo globalizado del Atlántico hispano como continuación y adaptación del mestizaje/casticismo, que a su vez representa la hegemonización de la "raza latina” decimonónica; de ahí la importancia de una genealogía de dicha formación racial.

\section{BiBLIOGRAFÍA}

Álvarez Junco, José. Mater Dolorosa. La idea de España en el siglo XIX. Madrid: Taurus, 2001.

Anderson, Benedict. Imagined Communities. Reflections on the Origin and Spread of Nationalism. Londres: Verso, 1983.

Andrews, George Reid. Afro-Latin America, 1800-2000. Nueva York: Oxford UP, 2004.

Ardao, Arturo. Génesis de la idea y el nombre de América Latina. Caracas: Centro de Estudios Latinoamericanos Rómulo Gallegos, 1980.

Beverley, John. Subalternity and Representation: Arguments in Cultural Theory. Durham: Duke UP, 1999.

Bilbao, Francisco. Iniciativa de la América: idea de un congreso federal de las repúblicas. México: Universidad Nacional Autónoma de México, 1978. La América en peligro. Buenos Aires: Ercilla, 1941. Evangelio americano. Caracas: Biblioteca Ayacucho, 1988.

Blumenbach, Johann Friedrich. The Anthropological Treatises of Johann Friedrich Blumenbach. Londres: Adamant, 2005. 
Brickhouse, Anna. Transamerican Literary Relations and the Nineteenth-Century Public. Nueva York: Cambridge UP, 2004.

Bueno Sánchez, Gustavo. "Fiesta de la Raza [desde 1913]. Día de la Raza [desde 1915]”. Proyecto Filosofía en español. 1 Oct. 2006 <http://www.filosofia.org/ ave/001/a220.htm>

Castelar, Emilio. Discursos parlamentarios. Madrid: Narcea de Ediciones, 1973.

Chevalier, Michel. Lettres sur l'Amérique du Nord. Princeton: Princeton UP, 1944.

Mexico: Before and After the Conquest. Filadelfia: Carey and Hart, 1846.

Doménech, Emmanuel. Journal d'un missionaire au Texas et au Mexique, par E. Doménech. 1846-1852. París: Gaume frères, 1857.

Escárraga, T. "El 30\% de los jóvenes españoles considera la inmigración 'perjudicial para la raza’”. El País Digital. Número 1631. Indexnet Santillana. 20 Oct. $2000<$ http://www.indexnet.santillana.es/rcs2/actualidad/ Bachillerato/2000-2001/08/raza.htm>

Fichte, J.G. Addresses to the German Nation. Nueva York: Harper, 1968. Schriften zur angewandten Philosophie. Frankfurt: Deutscher Klassiker Verlag, 1997.

Foucault, Michel. The Order of Things; An Archaeology of the Human Sciences. Nueva York: Vintage Books, 1973.

García Canclini, Néstor. Hybrid Cultures: Strategies for Entering and Leaving Modernity. Minneapolis: U of Minnesota P, 1995.

Consumers and Citizens: Globalization and Multicultural Conflicts. Minneapolis: U of Minnesota P, 2001.

La globalización imaginada. México: Paidós, 1999.

Gilroy, Paul. The BlackAtlantic: Modernity and Double Consciousness. Cambridge: Harvard UP, 1993.

Gobineau, Arthur de. The Inequality of Human Races. Nueva York: Howard Fertig, 1999.

González Prada, Manuel. Nuestros indios. Caracas: Universidad Central, 1983.

Graham, Richard. The Idea of Race in Latin America, 1870-1940. Austin: U of Texas P, 1990.

Henríquez Ureña, Pedro. Estudios mexicanos. México: Fondo de Cultura Económica, 1984.

Hostos, Eugenio María de. “El día de América”. Obras Completas. Vol. X: La Cuna de América. La Habana: Cultural, 1939. 11-19

"El Cholo”. Obras Completas. Temas sudamericanos. Vol. 7. La Habana: Cultural, 1939. 152-55. 
Kant, Immanuel. Observations of the Feeling of the Beautiful and Sublime. Berkeley: U of California P, 1960.

"On the Different Races of Man". Race and the Enlightenment. Emmanuel C. Eze, ed. Oxford: Blackwell, 1997. 38-48.

"Physical Geography". Race and the Enlightenment. Emmanuel C. Eze, ed. Oxford: Blackwell, 1997. 58-64.

Anthropology from a Pragmatic Point of View. Carbondale: Southern Illinois UP, 1978.

Linné, Carl von. "The God-given order of nature”. Race and the Enlightenment. Emmanuel C. Eze, ed. Oxford: Blackwell, 1997. 10-14.

Martí, José. "Nuestra América”. Obras Completas. Vol. 6. La Habana: Editorial Nacional de Cuba, 1963. 15-23.

“Mi Raza”. Obras Completas. Vol. 2. La Habana: Editorial Nacional de Cuba, 1963. 298-300.

Martín Márquez, Susan. Disorientations: Spanish Colonialism in Africa and the Cultural Mapping of Identity. New Haven: Yale UP, 2008.

Menéndez Pelayo, Marcelino. Estudios y discursos de crítica histórica y literaria. Santander: Aldus, S. A. de Artes Gráficas, 1941. 385-88.

Mignolo, Walter. The Idea of Latin America. Malten: Blackwell, 2005.

Miller, Marilyn Grace. Rise and Fall of the Cosmic Race: The Cult of Mestizaje in Latin America. Austin: U of Texas P, 2004.

Ortiz, Fernando. Contrapunteo cubano del tabaco y el azúcar. Caracas: Biblioteca Ayacucho, 1987.

Pérez Torres, Rafael. Mestizaje: Critical Uses of Race in Chicano Culture. Minneapolis: U of Minnesota P, 2006.

Poliakov, Leon. The History of Anti-Semitism. Nueva York: Vanguard Press, 1965.

Quinet, Edgar. L'expédition au Mexique. Londres: W. Jeffs, 1862.

Rama, Ángel. Transculturación narrativa en América Latina. México: Siglo XXI, 1982.

Rama, Carlos M. Historia de las relaciones culturales entre España y la América Latina. Siglo XIX. México: FCE, 1982.

Rodó, José Enrique. “Ariel”. Obras Completas. Buenos Aires: Antonio Zamora, 1948. 171-229.

Rojas Mix, Miguel. Los cien nombres de América. Barcelona: Lumen, 1991.

Romero, Vicente. “Du nominal 'latin' pourl’Autre Amérique. Notes sur la naissance et le sens du nom 'Amérique latine' autour des années 1850”. Histoire et sociétés de l'Amérique latine 7 (1998): 57-86.

Sierra, Justo. Evolución política del pueblo mexicano. México: FCE, 1950. 
Torres Caicedo, José. Unión latinoamericana. Pensamiento de Bolívar para formar una liga americana, su origen y desarrollo. París: Rosa y Bouret, 1865.

Ensayos biográficos y de crítica literaria sobre los principales poetas y literatos hispano-americanos. Vol. 1. Paris: Guillaumin, 1863.

Unamuno, Miguel de. Obras completas. 16 Vols. Madrid: A. Aguado, 19501958.

Vasconcelos, José. La raza cósmica. Buenos Aires: Espasa-Calpe, 1948. 